\title{
The descriptive epidemiology of craniopharyngioma
}

\section{Greta R. Bunin, Ph.D., Tanya S. Surawicz, M.P.H., Philip A. Witman, M.P.H., M.Phil., Susan Preston-Martin, Ph.D., Faith Davis, Ph.D., and Janet M. Bruner, M.D.}

Division of Oncology, Children's Hospital of Philadelphia, University of Pennsylvania School of Medicine, Philadelphia, Pennsylvania; Central Brain Tumor Registry of the United States, Division of Epidemiology and Biostatistics, School of Public Health, University of Illinois, Chicago, Illinois; Division of Chronic Disease Epidemiology, Department of Epidemiology and Public Health, Yale University School of Medicine, New Haven, Connecticut; University of Southern California, Norris Cancer Center, Los Angeles, California; and Department of Pathology, University of Texas, M.D. Anderson Cancer Center, Houston, Texas

The incidence of craniopharyngioma in the United States was estimated from two population-based cancer registries that include brain tumors of benign and borderline malignancy: the Central Brain Tumor Registry of the United States (CBTRUS) and Los Angeles county. Information on additional pediatric tumors was available from the Greater Delaware Valley Pediatric Tumor Registry (GDVPTR). The overall incidence of craniopharyngioma was 0.13 per 100,000 person years and did not vary by gender or race. A bimodal distribution by age was noted with peak incidence rates in children (aged 5-14 years) and among older adults (aged 65-74 years in CBTRUS and 50-74 years in Los Angeles county). Survival information was available from GDVPTR and the National Cancer Data Base (NCDB), a hospital-based reporting system. In the $\mathrm{NCDB}$, the 5-year survival rate was $80 \%$ and decreased with older age at diagnosis. Survival is higher among children and has improved in recent years. Approximately 338 cases of craniopharyngiomas are expected to occur annually in the United States, with 96 occurring in children from 0 to 14 years of age.

\section{Key Words * craniopharyngioma * incidence * survival}

The demographic patterns of craniopharyngioma are not well described because the tumor is rare. In addition, most cancer registries collect data only on malignant conditions and, therefore, they are not useful in the study of craniopharyngioma, considered to be of borderline histological malignancy. The objective of this report is to describe the epidemiology of craniopharyngioma. Incidence rates by gender, age, and race were calculated from three population-based cancer registries that include data on brain tumors of benign and borderline malignancy. Survival rates were estimated from a pediatric population-based tumor registry and a hospital-based registry.

\section{DATA COLLECTION METHODS}




\section{Tumor Incidence}

Data on the incidence of craniopharyngioma were available from three population-based registries: the Central Brain Tumor Registry of the United States (CBTRUS), Greater Delaware Valley Pediatric Tumor Registry (GDVPTR), and the University of Southern California/Los Angeles County Cancer Surveillance Program (CSP).

CBTRUS. The CBTRUS obtained data for the years 1990 to 1993 from 10 state cancer registries that catalog benign and malignant primary brain tumors: Arizona, Colorado, Connecticut, Delaware, Idaho, Maine, Minnesota, Montana, North Carolina, and Utah.[6] These registries are population based and reporting is required by law. The population data for each state were obtained from the Web site of the Surveillance, Epidemiology and End Results program, which receives yearly population estimates from the U.S. Bureau of the Census. For the analyses reported here, all diagnoses of craniopharyngioma (International Classification for Diseases of Oncology code 9350[12]) were included.

GDVPTR. The GDVPTR is a population-based registry of pediatric cancer that covers a 31-county region in the eastern U.S. consisting of eastern Pennsylvania, southern New Jersey, Delaware, and one northern Maryland county.[10] Approximately 1.8 million children under the age of 15 years live in the region. Incidents of cancers are registered if diagnosed on or after January 1, 1970, in a child aged less than 15 years, and who resided in the region at the time of diagnosis. For the period 1970 to 1989, cases were ascertained from all the major medical centers in the region and several centers outside the region that treated children with cancer. In addition, nearly all the other hospitals in the region that care for children reported cases. Although the GDVPTR relied on voluntary, mostly passive reporting, the incidence rates reported for this period are similar to other U.S. rates, such as those from the Surveillance, Epidemiology and End Results Program.[3,10,21] Only malignant neoplasms are generally registered, but benign and borderline brain tumors were ascertained for the period of 1970 to 1989 as part of a special project.

CSP. The University of Southern California/Los Angeles County CSP has collected reports on all new intracranial neoplasms diagnosed in the county population of almost 10 million people since 1972.[8] Inclusion criteria have been consistent, and reporting of both benign and malignant tumors has been at least 95\% complete since the beginning. Data were collected on 221 Los Angeles County residents with craniopharyngioma first diagnosed between 1972 and 1995. Specially trained CSP personnel abstract information from hospital charts on age, gender, race, address, religion, birthplace, occupation, and industry, as well as details of the pathological diagnosis.

Age-adjusted incidence rates were calculated by the direct method and standardized to the U.S. 1970 population.

\section{Survival Data}

Data were available from the GDVPTR and the National Cancer Data Base (NCDB).

NCDB. The NCDB, a joint project of the Commission on Cancer of the American College of Surgeons, requests data from hospitals in the United States with cancer registries. For the periods 1985 to 1988 and 1990 to 1992, data were available on intracranial tumors, including those in the pituitary, which were voluntarily electronically submitted to the NCDB from approximately 1000 hospitals. Of 68,042 records, 1064 were identified by the NCDB as duplicates and deleted. In addition, 3726 records were deleted because of invalid or illogical data. The remaining 63,252 records included 285 craniopharyngiomas, 
which are analyzed here. Observed survival estimates were generated with SAS,[16] using the life-table method with intervals of 1 month.[1]

GDVPTR. Survival estimates from the GDVPTR were generated in SAS version 6.03 using the Kaplan-Meier method. Comparisons of survival curves were made using the log-rank test. Observed survival rates were obtained from product-limit estimates of entire curves and were not adjusted for deaths due to other causes.

\section{RESULTS}

\section{Tumor Incidence}

In the 4-year period of 1990 to 1993, 135 craniopharyngiomas were diagnosed in the geographic areas of the CBTRUS. The incidence in males and females was nearly identical: 0.13 and 0.12 per 100,000 per year, respectively (Table 1). No racial difference in incidence was apparent, with a rate of 0.12 in Caucasians and 0.13 in African Americans.

\begin{tabular}{|c|c|c|c|c|c|}
\hline AVERAGE AN & NUAL INCI & $\begin{array}{l}\text { T } \\
\text { IDENCE RAT } \\
\text { RACE, }\end{array}$ & $\begin{array}{l}\text { ABLE } 1 \\
\text { ES OF CRANIOPHARYNGION } \\
\text { AND REGISTR* }\end{array}$ & YV GENDE & \\
\hline CBTRUS, & $990-1993$ & & Los Angeles Count & $1972-19$ & \\
\hline & $\begin{array}{l}\text { No. of } \\
\text { Tumors }\end{array}$ & $\begin{array}{l}\text { Incidence } \\
\text { Rate }\end{array}$ & & $\begin{array}{l}\text { No. of } \\
\text { Tumors }\end{array}$ & $\begin{array}{c}\text { Incidence } \\
\text { Rate }\end{array}$ \\
\hline $\begin{array}{l}\text { total } \\
\text { male } \\
\text { female } \\
\text { Caucasians } \\
\text { African Americans }\end{array}$ & $\begin{array}{r}135 \\
68 \\
67 \\
109 \\
11\end{array}$ & $\begin{array}{l}0.13 \\
0.13 \\
0.12 \\
0.12 \\
0.13\end{array}$ & $\begin{array}{l}\text { total } \\
\text { male } \\
\text { female } \\
\text { Caucasian males } \\
\text { African American males } \\
\text { Caucasian females } \\
\text { African American females }\end{array}$ & $\begin{array}{r}221 \\
118 \\
103 \\
62 \\
12 \\
59 \\
11\end{array}$ & $\begin{array}{l}\text { NÁ } \\
0.13 \\
0.11 \\
0.14 \\
0.12 \\
0.11 \\
0.10\end{array}$ \\
\hline $\begin{array}{l}{ }^{*} \text { Rates are per } 1 \\
\text { ondation. NA }=n\end{array}$ & $000 \mathrm{p}$ & on years & and age-adjusted using th & $970 \mathrm{U}$ & standard \\
\hline
\end{tabular}

Incidence seemed to vary with patient age, being somewhat higher in patients aged 5 to 14 years than in any other age group except those aged 65 to 74 years (Fig. 1). In late adolescence and early adulthood (aged 15-34 years), incidence was the lowest. Starting at age 35 years, incidence appeared fairly constant except for a higher rate in patients aged 65 to 74 years and the absence of any cases after the age of 84 years. Given the small numbers of craniopharyngiomas in any age group, the observed differences could have occurred by chance. 


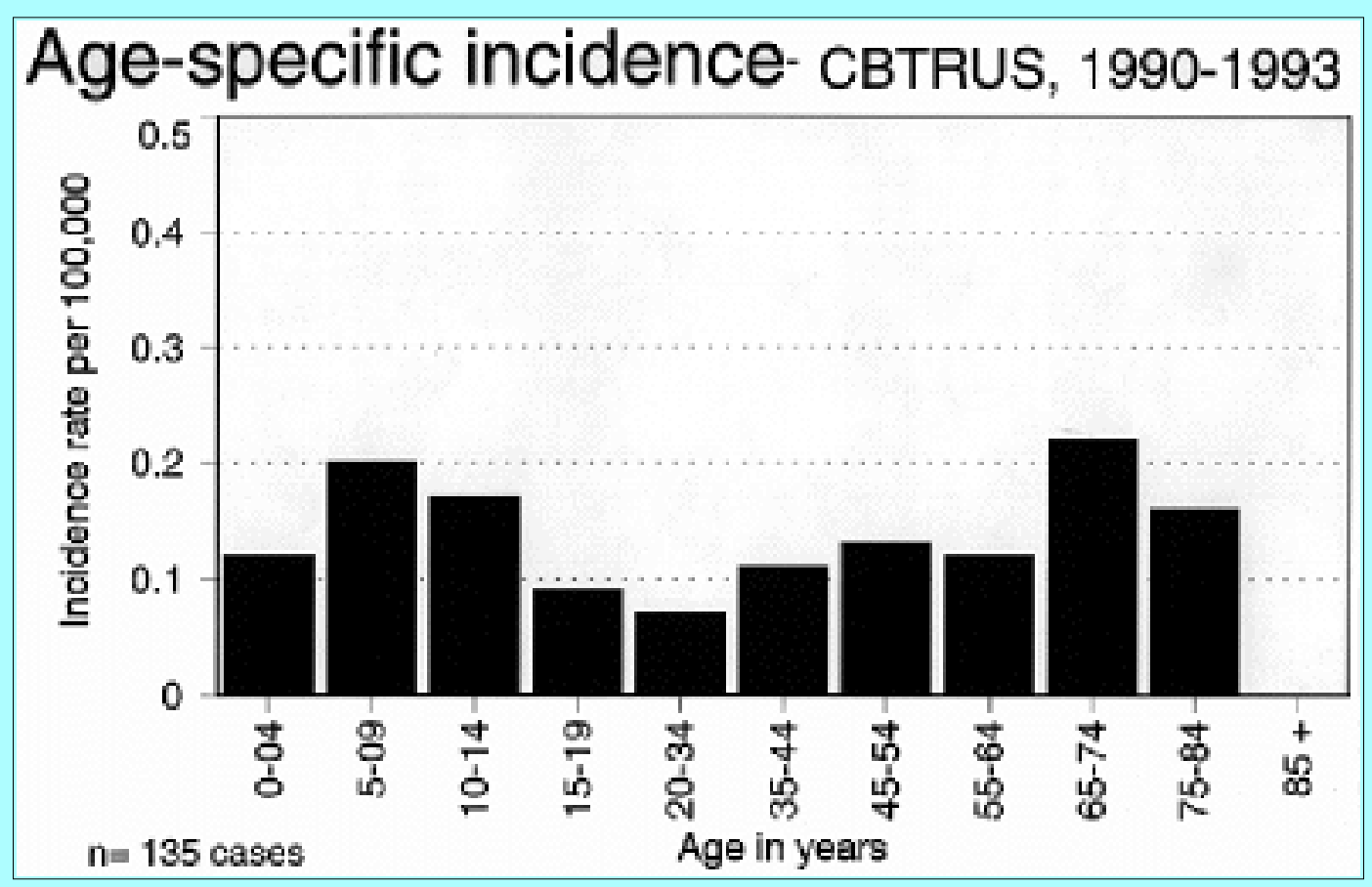

Fig. 1. Graph showing the age-specific incidence of craniopharyngioma derived from the CBTRUS data.

In Los Angeles county, 221 craniopharyngiomas were diagnosed between 1972 and 1995. The incidence rates by gender ( 0.13 in males and 0.11 in females) are comparable to those ascertained by CBTRUS (Table 1), and no racial differences were noted. Higher rates were noted among children (aged 5-14 years) and older adults (aged 50-74 years) (Fig. 2). The lowest incidence occurred among those aged 15 to 34 years.

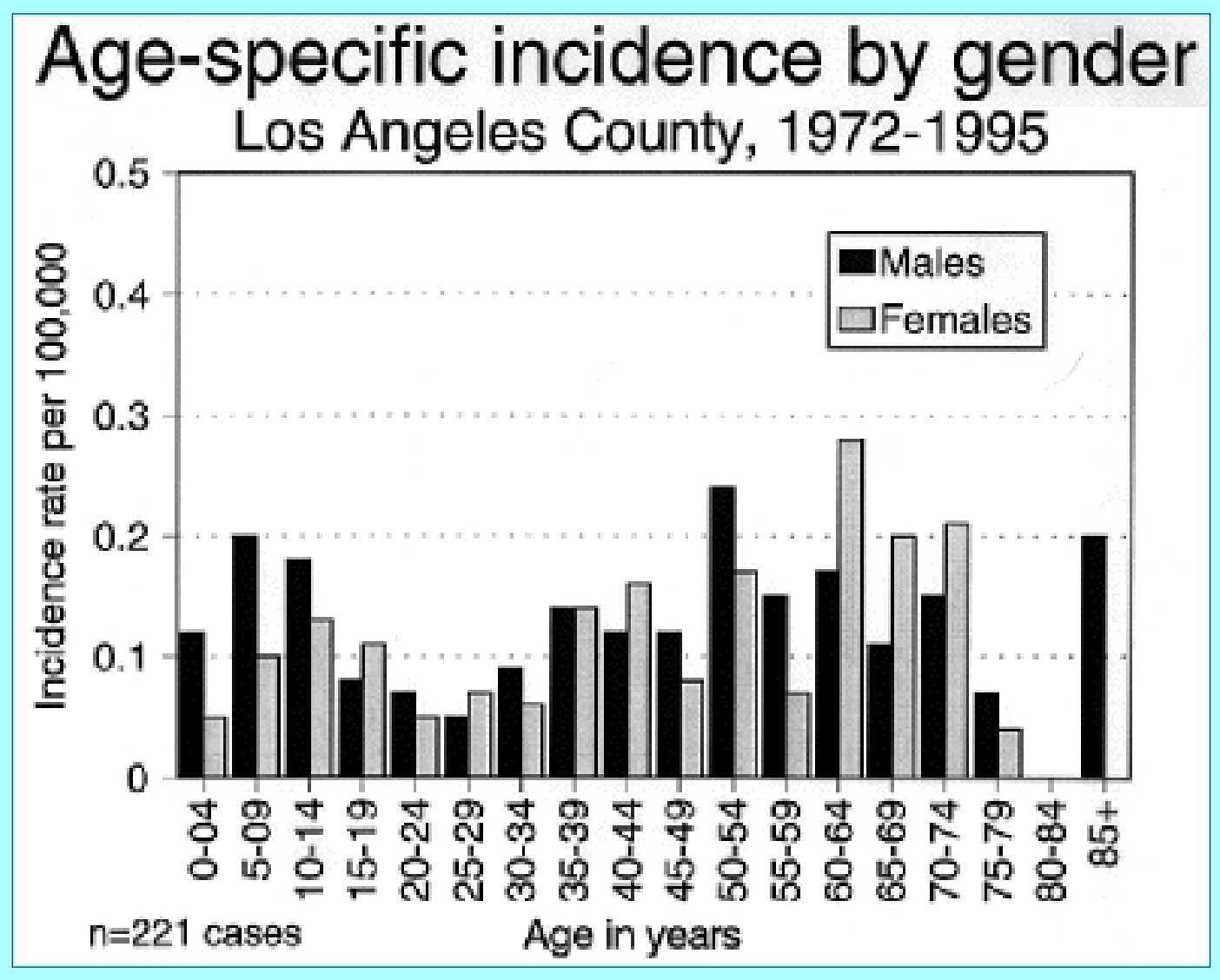

Fig. 2. Graph showing the age-specific incidence of craniopharyngioma derived from the 
University of Southern California/Los Angeles county CSP data.

In the GDVPTR area, 67 craniopharyngiomas were diagnosed in children aged 0 to 14 years between 1970 and 1989, giving an incidence rate of 0.18 per 100,000 per year, a rate similar to children in the CBTRUS areas (Table 2). The incidence in children in the GDVPTR regions did not differ by gender but was significantly higher in African Americans compared to Caucasians. No craniopharyngiomas occurred in children who were neither Caucasian or African American; two tumors would have been expected if children of other races experienced the same incidence as the population as a whole.

\begin{tabular}{|c|c|c|c|c|c|c|c|c|}
\hline \multirow[b]{3}{*}{$\begin{array}{l}\text { Age } \\
\text { Group (yrs) }\end{array}$} & \multicolumn{4}{|r|}{$\begin{array}{l}\text { TABLE } 2 \\
\text { ES IN CH LD }\end{array}$} & \multirow{2}{*}{\multicolumn{2}{|c|}{ EN WITH CRANIOPH }} & \multirow{2}{*}{\multicolumn{2}{|c|}{ RYNGOMk }} \\
\hline & \multicolumn{2}{|c|}{ CBTRUS } & \multicolumn{2}{|c|}{ GDVPTR } & & & & \\
\hline & $\begin{array}{l}\text { No. of } \\
\text { Tumors }\end{array}$ & $\begin{array}{l}\text { Incidence } \\
\text { Rate }\end{array}$ & $\begin{array}{l}\text { No. of } \\
\text { Tum ors }\end{array}$ & $\begin{array}{l}\text { Incidence } \\
\text { Rate }\end{array}$ & $\begin{array}{l}\text { No. of } \\
\text { Tumors }\end{array}$ & $\begin{array}{l}\text { Incidence } \\
\text { Rate }\end{array}$ & $\begin{array}{l}\text { No. of } \\
\text { Tum ors }\end{array}$ & $\begin{array}{l}\text { Incidence } \\
\text { Rate }\end{array}$ \\
\hline $\begin{array}{c}0-4 \\
5-9 \\
10-14\end{array}$ & $\begin{array}{l}10 \\
16 \\
14\end{array}$ & $\begin{array}{l}0.12 \\
0.20 \\
0.17\end{array}$ & $\begin{array}{l}15 \\
34 \\
18\end{array}$ & $\begin{array}{l}0.13 \\
0.27 \\
0.13\end{array}$ & $\begin{array}{l}10 \\
15 \\
13\end{array}$ & $\begin{array}{l}0.12 \\
0.20 \\
0.18\end{array}$ & $\begin{array}{l}4 \\
7 \\
9\end{array}$ & $\begin{array}{l}0.05 \\
0.10 \\
0.13\end{array}$ \\
\hline${ }^{x} \mathrm{LA}=$ & ngele & county. & & & & & & \\
\hline
\end{tabular}

\section{Survival Rates}

The NCDB included data on 285 patients with craniopharyngioma, 35 of whom died. Survival percentage was estimated to be $86 \%$ at 2 years and $80 \%$ at 5 years postdiagnosis. Survival varied notably by age group, with excellent survival for patients under the age of 20 years and poor survival for those over the age of 65 years (Table 3 ).

In the population-based GDVPTR, children with craniopharyngioma had a 5-year survival rate of 83\%, which was lower than that for children in the NCDB data. The NCDB data are from the late 1980s and early 1990s whereas the GDVPTR data include a time period beginning in 1970. The most recent time period in the GDVPTR data, 1985 to 1989, is similar to the period of NCDB data. For patients diagnosed with craniopharyngioma in 1985 to 1989 in the GDVPTR region, 5-year survival is $94 \%$ based on 16 patients and one death compared to $99 \%$ in the NCDB data with 72 patients and two deaths.

\begin{tabular}{|c|c|c|c|c|}
\hline \multicolumn{5}{|c|}{$\begin{array}{c}\text { TABLE } 3 \\
\text { NATONAL CANCER DATA BASE 5-VEAR SURVNAL RATES IN PATIENTS WITH } \\
\text { CRANIOPHARVNGOMA BV AGE AT DIAGNOS I }\end{array}$} \\
\hline $\begin{array}{l}\text { Age at } \\
\text { Diagnosis }\end{array}$ & $\begin{array}{l}\text { No. of } \\
\text { Patierts }\end{array}$ & $\begin{array}{l}\text { No. of } \\
\text { Deaths }\end{array}$ & $\begin{array}{c}\text { Survival } \\
\text { Pate }\end{array}$ & $95 \% \mathrm{Cl}^{*}$ \\
\hline $\begin{array}{l}\times 20 \\
20-64 \\
\Xi 65\end{array}$ & $\begin{array}{r}82 \\
168 \\
35\end{array}$ & $\begin{array}{l}2 \\
21 \\
12\end{array}$ & $\begin{array}{l}0.99 \\
0.79 \\
0.37\end{array}$ & $\begin{array}{l}0.96-1 \\
0.71-0.88 \\
0.08-0.66\end{array}$ \\
\hline man & intor & & & \\
\hline
\end{tabular}

\section{DISCUSSION}

The overall incidence of craniopharyngioma observed in the CBTRUS and Los Angeles county data is similar to that seen in other populations. Stiller and Nectoux[20] reported a similar rate in U.S. data combined from several areas that do not overlap with the states that contributed to the CBTRUS data. The incidence in Rochester, Minnesota, was higher (0.3) but was based on only six tumors.[13] 
In the present study, virtually identical incidence rates were seen in Caucasians and African Americans. Similarly, in Stiller and Nectoux's[20] U.S. data, the rates were 0.07 for Caucasians and 0.10 for African Americans, an insignificant difference. Among children in the CBTRUS data, no substantial racial difference was observed. However, in the GDVPTR data, the rate in African-American children appeared to be approximately twice that in Caucasian children, a statistically significant difference. The discrepant incidence rates might have occurred by chance, given the small number of African-American cases, (four in the CBTRUS data and 20 in the GDVPTR data). A geographic difference in the incidence rates in African Americans is also a possible explanation.

We did not observe any differences in incidence between males and females, overall or by gender among children. There was also no gender difference in a population-based study in Finland.[18] However, in a large hospital-based series of cases from the United Kingdom, there were 107 males and 66 females, a ratio of 1.3.[14] In case series of craniopharyngiomas in children, the male/female ratios were 0.9 based on 42 tumors[7] and 1.6 based on 105 tumors.[19] Considering all the data, craniopharyngioma may occur slightly more often in boys.

These data suggest that a smaller proportion of all craniopharyngiomas occur in childhood. Roughly one-third of the patients in our study were under 20 years of age at the time of diagnosis (35\% in CBTRUS, $33 \%$ in Los Angeles county). Previous studies have reported that $50 \%$ of craniopharyngiomas occurred in children.[2,17]

A bimodal age distribution of incidence rates is apparent in the CBTRUS and Los Angeles county data. Although the numbers of cases in each age category are limited, the pattern is consistent in both populations with larger peaks noted in older adults (Figs. 1 and 2). Whereas increasing mortality rates from all brain tumors among the elderly have been correlated with increased use of diagnostic procedures, especially among people 65 years of age and older covered by Medicare,[11] the increased incidence among adults in Los Angeles county occurs between the ages of 50 and 74 years and is not likely due to a diagnostic bias in the elderly. Large clinical series have suggested a bimodal distribution and noted different histologies in younger and older patients: adamantinous tumors are more common in children and squamous papillary tumors are more common in adults.[4,5,15] These data suggest that there may be two distinct etiologies for the younger and the older patients. Craniopharyngiomas are coded under a single morphology code in the International Classification for Diseases of Oncology; therefore, it not possible to distinguish these subtypes in our data.

Craniopharyngioma is believed to develop from rests of embryonal cells in the pituitary. Two hypotheses have been proposed: the first relates to the development of the adenohypophysis during embryogenesis, which is consistent with pediatric tumor development; the second proposes that residual squamous epithelium from the adenohypophysis undergoes metaplasia, which explains the adult tumors.[15] A consensus on this has not been achieved. It may be of value to note that other tumors believed to develop from embryonal cells, such as neuroblastoma and medulloblastoma, occur at much higher rates in children than in adults, although the fraction occurring during childhood differs among these embryonal tumors.

There is some suggestion of international variation in incidence of these tumors which is often taken to suggest an environmental etiology. For example, Stiller and Nectoux[20] have reported that the proportion of central nervous system tumors that are craniopharyngioma varied substantially; the percentages were $1.5 \%$ in Australia, 4.7 to $7.9 \%$ in Europe, $3.9 \%$ in Japan, $2.7 \%$ in U.S. Caucasians, 
4.9\% in U.S. African Americans, and $11.6 \%$ in Africa. Because it is likely that not all brain tumors are diagnosed in developing countries, variation in incidence will be exaggerated. Percentages are useful in comparing international rates because they will be less influenced by incomplete reporting. However, percentages are influenced by the proportions of other types of tumors, including those with nonspecific diagnosis such as brain tumor or malignant brain tumor. Although the international comparison suggests that craniopharyngioma occurs more frequently in Africa and less frequently in Australia, conclusions are not possible.

In the NCDB data, the survival rate at 5 years was $80 \%$ overall, with survival much better among children than the elderly. Observed survival is expected to be lower in the elderly, as our survival estimates were not adjusted for death due to other causes. This contrasts with a 1973 report in which adults fared better than children.[9] Reports on survival in the literature are difficult to interpret because some are based on patients who received treatment and, therefore, had to survive long enough to do so. To our knowledge, the only population-based report of survival after diagnosis of craniopharyngioma is an analysis of data from the Finnish Cancer Registry for patients diagnosed from 1951 to 1982.[18] The overall 5-year survival rate was 69\%; $73 \%$ for patients diagnosed in the 1970s. Neurosurgical techniques and the introduction of computerized tomography scanning have led to lower surgical mortality rates and more complete resections and, therefore, improved survival. The survival rate in the NCDB data for patients diagnosed from 1985 to 1992 was slightly higher than in the report from Finland. The NCDB is hospital based but does include all patients diagnosed at the participating hospitals, regardless of treatment.

\section{CONCLUSIONS}

In summary, craniopharyngiomas are a rare brain tumor of uncertain behavior that occur at a rate of 1.3 per million person years. Incidence rates are similar in males and females and between Caucasians and African Americans. Tumors are more common among children (aged 5 to 14 years) and older adults (aged 65 to 74 years in CBTRUS and 50 to 74 years in Los Angeles county); the lowest rates occur among those aged 15 to 34 years. Survival is highest for patients diagnosed at a younger age and has improved for children diagnosed since the mid-1980s. Based on the rates reported here, 338 cases are expected to occur annually in the U.S. with 96 occurring in children 0 to 14 years of age.

\section{Acknowledgments}

The registries and participants who provide data to CBTRUS include: Arizona Cancer Registry, Georgia Yee; Colorado Central Cancer Registry, Robin Bott; Connecticut Tumor Registry, John Flannery; Delaware State Tumor Registry, Carol Marker; Cancer Data Registry of Idaho, Stacey Carson; Maine Cancer Registry, Melanie Lanctot; Massachusetts Cancer Registry, Susan Gershman; Minnesota Cancer Surveillance System, Sally Bushhouse; Missouri Cancer Registry, Jian Chang; Montana Central Tumor Registry, Debbi Hellhake; North Carolina Central Cancer Registry, Rebecca Martin; and Utah Cancer Registry, Rosemary Dibble and Janet Stanford.

The authors thank the NCDB Data Request Committee and Mr. Herman Menck of the American College of Surgeons for providing the NCDB data.

\section{References}

1. Armitage P, Berry G: Statistical Methods in Medical Research, ed 2. Oxford: Blackwell Scientific, 
2. Barrow DL, Tindall GT: Tumors of the pituitary gland, in Morantz RA, Walsh JW (eds): Brain Tumors: A Comprehensive Text. New York: Marcel Dekker, 1994, pp 367-386

3. Bunin GR, Feuer EJ, Witman PA, et al: Increasing incidence of childhood cancer: report of 20 years experience from the Greater Delaware Valley Pediatric Tumor Registry. Paediatr Perinat Epidemiol 10:319-338, 1996

4. Burger PC, Scheithauer BW, Vogel FS: Surgical Pathology of the Nervous System and its Coverings, ed 3. New York: Churchill Livingstone, 1991

5. Carmel PW: Brain tumors of disordered embryogenesis, in Youmans JR (ed): Neurological Surgery: A Comprehensive Reference Guide to the Diagnosis and Management of Neurosurgical Problems, ed 3. Philadelphia: WB Saunders, 1990, Vol 5, pp 3223-3249

6. CBTRUS: 1996 Annual Report. Chicago: Central Brain Tumor Registry of the United States, 1997 7. Farwell JR, Dohrmann GJ, Flannery JT: Central nervous system tumors in children. Cancer 40:3123-3132, 1977

8. Hisserich JC, Preston-Martin S, Henderson BE: An areawide cancer reporting network. Publ HIth Rep 90:15-17, 1975

9. Kahn EA, Gosch HH, Seeger JF, et al: Forty-five years experience with the craniopharyngiomas. Surg Neurol 1:5-12, 1973

10. Kramer S, Meadows AT, Jarrett P, et al: Incidence of childhood cancer: experience of a decade in a population-based registry. J Natl Cancer Inst 70:49-55, 1983

11. Modan B, Wagener DK, Feldman JJ, et al: Increased mortality from brain tumors: a combined outcome of diagnostic technology and change of attitude toward the elderly. Am J Epidemiol 135:1349-1357, 1992

12. Percy C, Van Holten V, Muir C (eds): ICD-O International Classification of Diseases for Oncology, ed 2. Geneva: World Health Organization, 1990

13. Radhakrishnan K, Mokri B, Parisi JE, et al: The trends in incidence of primary brain tumors in the population of Rochester, Minnesota. Ann Neurol 37:67-73, 1995

14. Rajan B, Ashley S, Gorman C, et al: Craniopharyngioma--long-term results following limited surgery and radiotherapy. Radiother Oncol 26:1-10, 1993

15. Samii M, Tatagiba M: Craniopharyngioma, in Kaye AH, Laws ER Jr (eds): Brain Tumors: An Encyclopedic Approach. New York: Churchill Livingstone, 1995, pp 873-894

16. SAS/STAT User's Guide, Version 6, ed 4. Cary, NC: SAS Institute, Vols 1, 2, 1988

17. Scott RM, Pomeroy SL, Tarbell NJ: Craniopharyngioma, in Black PM, Loeffler JS (eds): Cancer of the Nervous System. Cambridge, MA: Blackwell Science, 1997, pp 414-422

18. Sorva R, Heiskanen O: Craniopharyngioma in Finland. A study of 123 cases. Acta Neurochir 
81:85-89, 1986

19. Stewart AM, Lennox EL, Sanders BM: Group characteristics of children with cerebral and spinal cord tumors. Br J Cancer 28:568-574, 1973

20. Stiller CA, Nectoux J: International incidence of childhood brain and spinal tumors. Int J Epidemiol 23:458-464, 1994

21. Young JL, Miller RW: Incidence of malignant tumors in U.S. children. J Pediatr 86:254-258, 1975

Manuscript received October 10, 1997.

Accepted in final form November 20, 1997.

This work was conducted under contract to the Central Brain Tumor Registry of the United States and supported by the Pediatric Brian Tumor Foundation of the United States through the Ride for Kids Fundraising Program, sponsored by the American Honda Motor Company, Motorcycle Division.

Cancer incidence data for Los Angeles County were collected with support from grant CA17054 and contract N01-CN-25403 from the National Institutes of Health and subcontracts 050(C-L)-8709 from the California Department of Health Services as part of its statewide cancer reporting system.

Address reprint requests to: Tanya S. Surawicz, M.P.H., Central Brain Tumor Registry of the United States, Division of Epidemiology and Biostatistics, School of Public Health, University of Illinois, 2121 West Taylor Street, Chicago, Illinois 60612. email: surawicz@uic.edu 